\title{
Bilateral renal venous thrombosis and adrenal hemorrhage: sequential prenatal US with postnatal recovery
}

Keith K. Lau • Erik Fernandez y Garcia •

Winnie Y. Kwan • Lindsey Albrecht •

Rebecca Stein-Wexler

Published online: 5 July 2007

(C) Springer-Verlag 2007

Erratum to: Pediatr Radiol

DOI 10.1007/s00247-007-0522-1

The name of the second author was abbreviated incorrectly in the affiliations section on the title page.

E.F. y Garcia should read E. Fernandez y Garcia.

The online version of the original article can be found at http://dx.doi. org/10.1007/s00247-007-0522-1

K. K. Lau • E. Fernandez y Garcia · W. Y. Kwan · L. Albrecht Department of Pediatrics, University of California, Davis,

Sacramento, CA, USA

R. Stein-Wexler $(\square)$

Department of Radiology, University of California,

Davis, 4860 Y St., Suite 3100,

Sacramento, CA 95817, USA

e-mail: rebecca.steinwexler@ucdmc.ucdavis.edu 